\title{
Monitoring System of Environment Noise and Pattern Recognition
}

\author{
Luis Pastor Sánchez Fernández, Luis A. Sánchez Pérez, José J. Carbajal Hernández \\ Instituto Politécnico Nacional, Centro de Investigación en Computación \\ Av. Juan de Dios Bátiz s/n, Col. Nueva Industrial Vallejo, C.P. 07738, México, D.F. \\ 1sanchez@cic.ipn.mx, 1.alejandro.2011@gmail.com, carbajalito@hotmail.com
}

Received: January 15, 2021 Revised: February 12, 2021. Accepted: March 3, 2021. Published: March 24, 2021.

\begin{abstract}
This paper presents an overview of the wireless monitoring system of environment noise, placed throughout Historical Centre of México City which represents an attractive technological innovation. It takes permanent measurements of noise levels and stream the data back to the main monitoring station every five minutes and the measurements of noise produced during the take-off in a location of the International Airport. The data acquisition is made at $25 \mathrm{KHz}$ at 24 bits resolution. This work allows analyzing the urban noise level and its frequency range. Additionally, a computational model for aircraft recognition using take-off noise spectral features is analyzed based on other previous results. Eight aircraft categories with all signals acquired in real environments are used. The model has an identification level between 65 and $70 \%$ of success. These spectral features are used to allow comparison with other aircraft recognition methods using speech processing techniques in real environments. This system type helps to foresee potential effects to health of environment noise.
\end{abstract}

Keywords—noise, aircraft, pattern, recognition, monitoring.

\section{INTRODUCTION}

The heavy traffic during the morning and evening rush hours creates a noise problem that is difficult to address. The noise emissions should be no more than $68 \mathrm{~dB}(\mathrm{~A})$ during the day and $65 \mathrm{~dB}(\mathrm{~A})$ at night. However, the noise level in most areas has been measured between 77 and $82 \mathrm{~dB}(\mathrm{~A})$. The aircraft classification is based on the principle that the airline should pay a fair price that should be proportional to its noise impact, independently of the weight of the aircraft or of the transport service rendered. Committees of Aerial Transport and Environmental propose an aircraft classification based on the level of noise emission [1], [2].

This aircraft recognition, based on the preprocessed spectral features allows the comparison with other aircraft recognition methods using feature extraction with speech processing techniques, a neural model more complex and measurement segmentation in time, all in real environments [3], [4]. Some discussions have commented on the potential usefulness and feasibility of these preprocessed spectral features of take-off noise for the aircraft recognition. Their lower performance is demonstrated in this paper.

The monitoring system is presented in Fig. 1. Each node includes a half-inch prepolarized IEC 61672 Class 1 microphone [5], [6] with a windscreen, rain protection, and bird spike mounted $4 \mathrm{~m}$ above the road surface in a weatherproof case, a data acquisition a card of dynamic range, an industrial computer and wireless connection to Internet by means of $3 \mathrm{G}$ Mobile Broadband. Each node measures the noise levels every 30 seconds and streams the data back to the main monitoring station every five minutes. A portable node measures the noise produced during the take-off at International Airport. Fig. 2 shows an example of urban noise patterns of two weeks in the Historical Centre of México City. These patterns will be analyzed in a next stage.

Aircraft classification base on take-off noise becomes a complicated problem when it is done in real environments because the background noise, the weather, the speed of the take-off and even the aircraft's load can interfere with the correct detection. Some devices with neural networks recognize the aircraft class, but they can only discriminate between jet aircrafts, propeller aircrafts, helicopters and background noise [7].

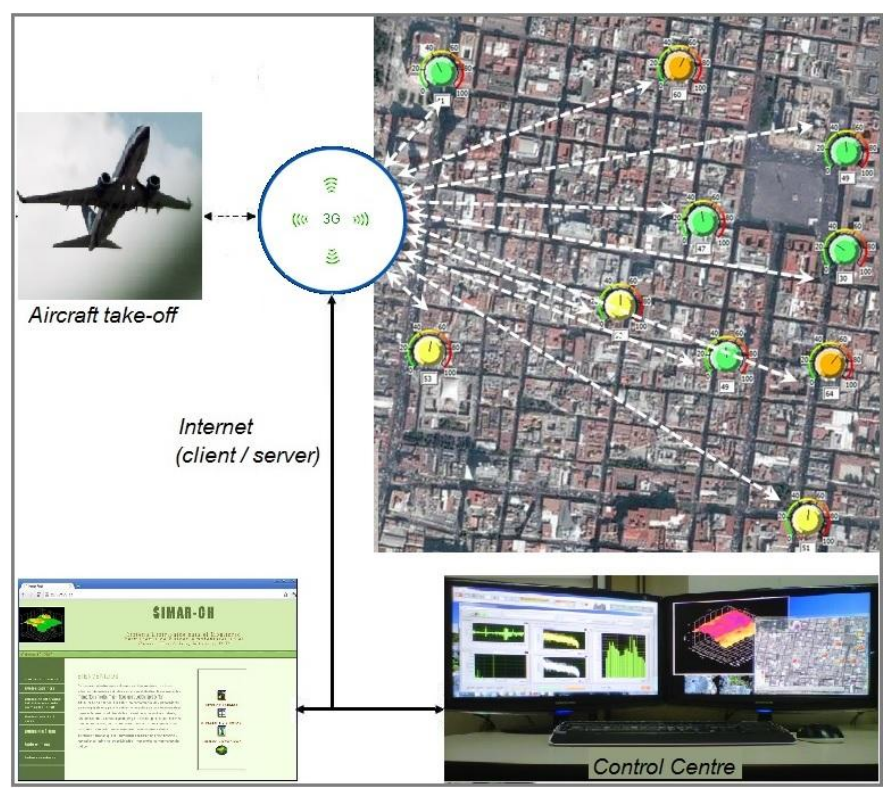

Fig. 1. Monitoring system of environment noise in México City 


\section{WIRELESS MONITORING SYSTEM}
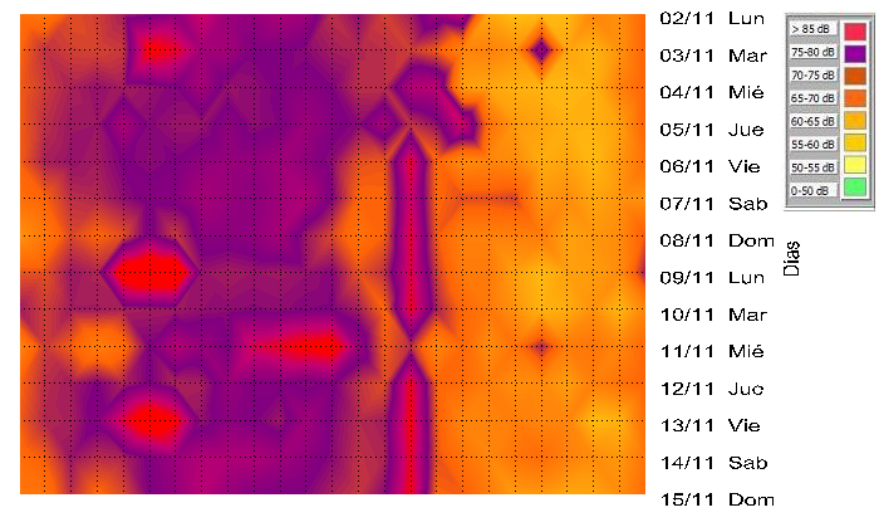

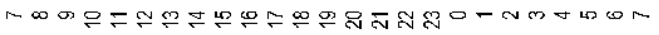

Horas

Fig. 2. Noise patterns of two weeks. Node placed at Corregidora and Pino Suárez in Historical Centre of México City

Wireless topology reduces costs and provides flexibility in setting up the monitoring systems. Each monitoring node is based on a headless industrial PC running Windows XP with a Wi-Fi adapter and a NI USB-9234 dynamic signal analyzer (DSA).

The system is designed so it can keep collecting data locally for up to 14 days. The government plans to use the acquired data to identify worst times and locations, create noise maps, and to implement regulatory actions to control and prevent the noise and promote a healthier "noise" environment and bring the city up to par with other big cities worldwide. In addition to traditional metrics used for road traffic noise such as Leq (equivalent sound level) at different averaging periods and times of day, the system is capable of recording fractional octave analysis and measuring prominent tones.

If the system analyst makes a request, the nodes are capable of transferring audio files to Central Server, for study of transient signals that may trigger alarms. This is helpful in the identification of isolated sound sources that cause annoyance.

The preliminary strategy was to use the public Wi-Fi in the area which was installed in 2008, but for lack of coverage in all nodes, the communication migrated to $3 \mathrm{G}$ (International Mobile Telecommunications-2000 IMT-2000) system provided by a wireless carrier in areas without signal of public Wi-F. 3G allows simultaneous use of speech and data services and significantly slower data rates around 5.8 Mbps on the uplink to the data center compared to the 54 to $100 \mathrm{Mbps}$ possible with $801.11 \mathrm{X}$.
IEEE 802.11 divides the band from 2400 to $2483.5 \mathrm{GHz}$ into channels, analogously to how radio and TV broadcast bands are carved up but with greater channel width and overlap. For example the $2.4000-2.4835 \mathrm{GHz}$ band is divided into 13 channels each of width $22 \mathrm{MHz}$ but spaced only $5 \mathrm{MHz}$ apart, with channel 1 centered on $2.412 \mathrm{GHz}$ and 13 on $2.472 \mathrm{GHz}$. By reserving certain channels for the noise monitoring system, they may be able to eliminate the slower $3 \mathrm{G}$ connection when they expand it.

\section{COMMUNICATION PROCEDURE BASED ON TCP/IP}

The nodes (measurement points) have a dynamic address assigned by a DHCP server (Dynamic Host Configuration Protocol). The Control Center has a IP Static address.

Control Center is comparable to a server. Nodes are similar to a Client. The nodes attempt to initiate the connection (open a Connection TCP). IF the Control Center receives this request of connection, which is validated with a key that must send each node, admits the connection.

Connections TCP/IP stay open. Each node hopes by the data request of the Control Center. The basic period of data request is 5 minutes.

Figures 3, 4 and 5 present examples of monitoring of environment noise for the Historical Centre of México City. Weighting filter A and C may be used [8], [9], [10].

\section{NOISE CHARACTERISTICS OF AIRCRAFT TAKING OFF}

The Fig. 6 presents the system block diagram for the pattern generation and recognition. The take-off noise is considered a non-stationary transient signal because it starts and ends in a zero level and it has a finite duration [10].

Figure 7 presents the time-domain representation of a takeoff noise typical signal. Fig. 8 shows, most of the signal energy is below $2.5 \mathrm{KHz}$. In this case, apart from the fact that the signal starts and ends in a zero level, the background noise is more notorious in the ends of the signal because in the central part, the aircraft-generated noise masks it.

For all used aircraft noises the typical form of the amplitude spectrum is observed from 0 to $5000 \mathrm{Hertz}$, for this reason, in this work was used a sampling frequency of 25000 $\mathrm{Hz}$ (samples per second). The amplitude spectrum has 300000 harmonics with resolution of $0.04167 \mathrm{~Hz}$. 


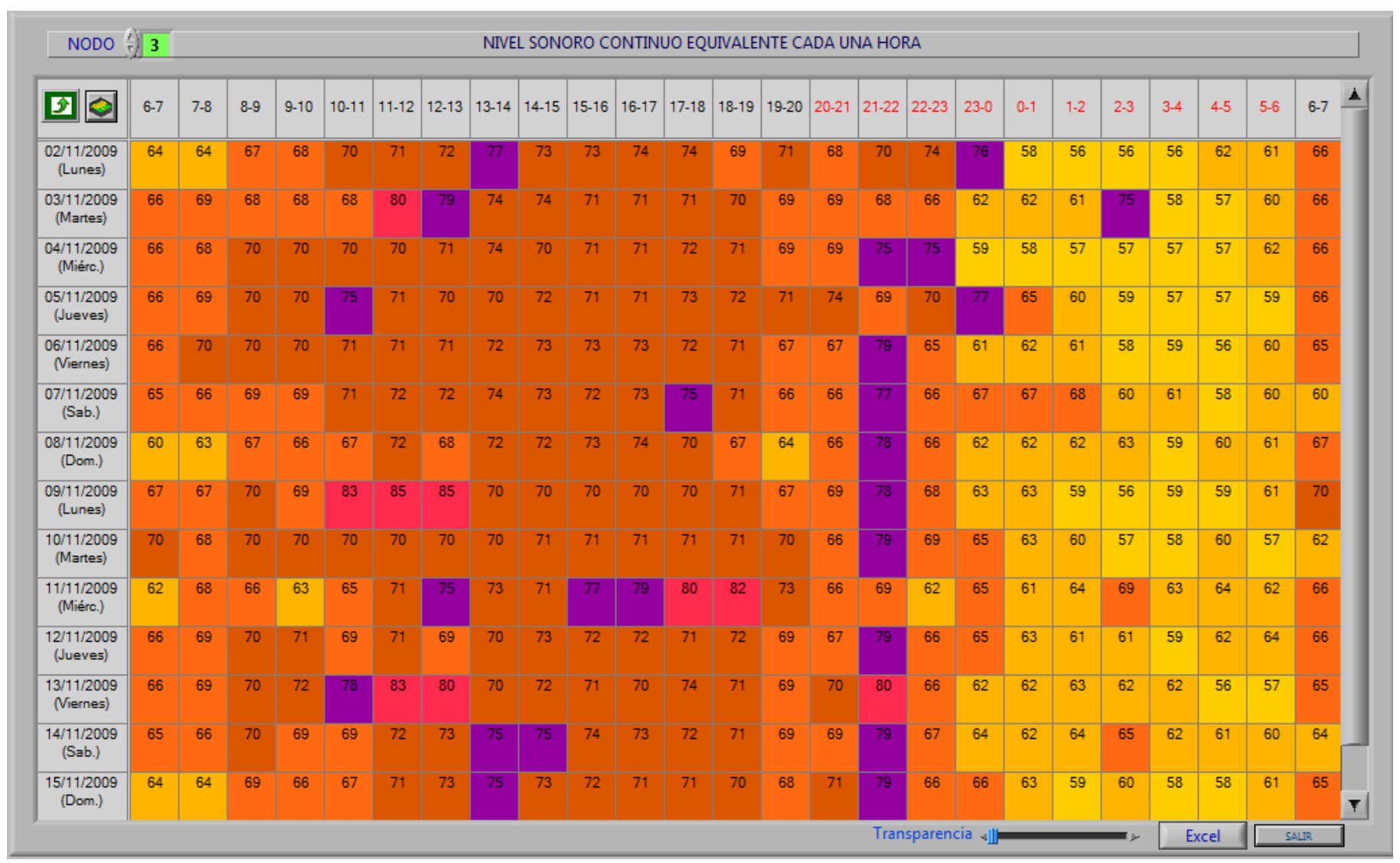

Fig. 3. Noise level, time, date, and amplitude (dBA). Node placed at Corregidora and Pino Suárez in Historical Centre of México City

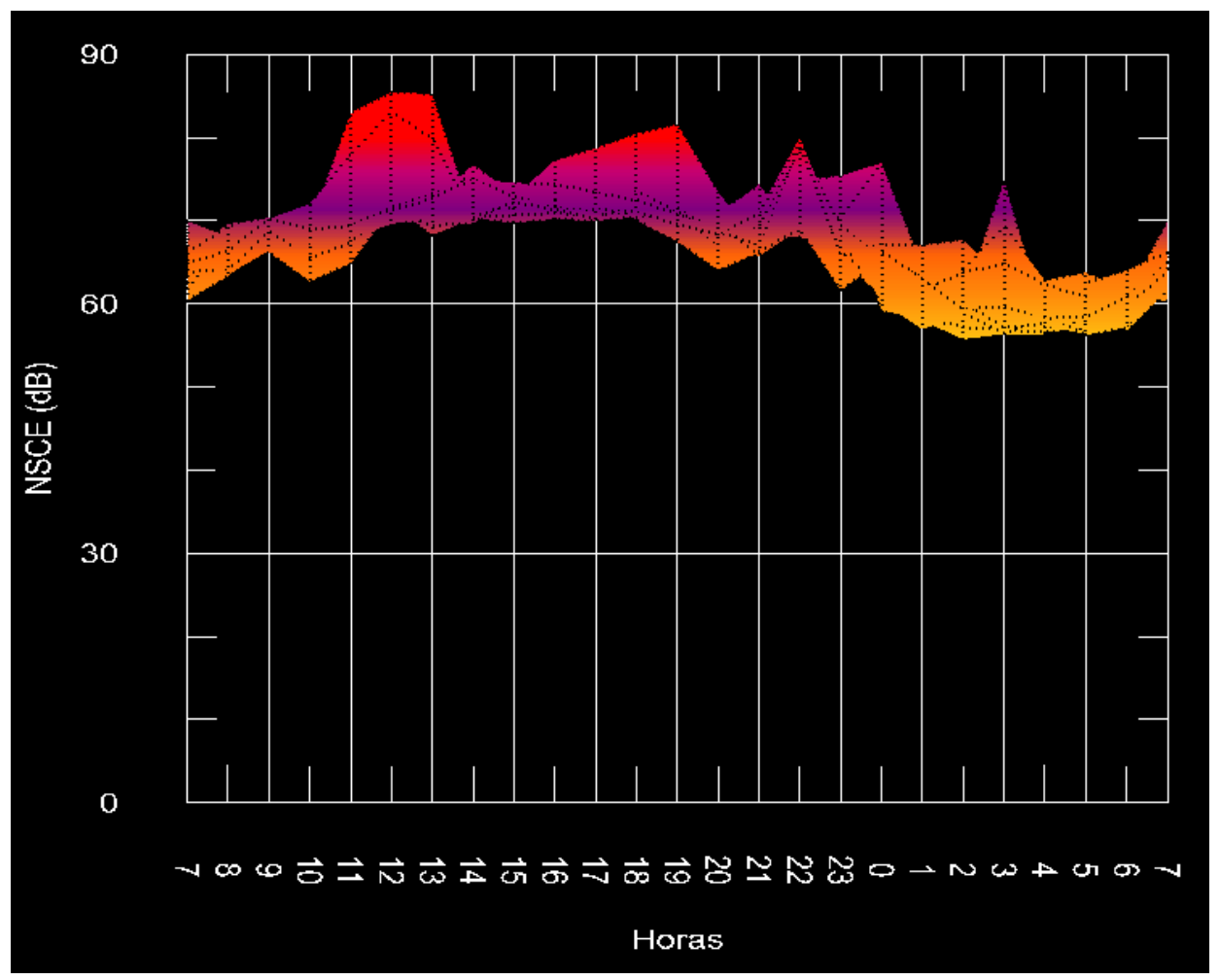

Fig. 4. Noise map displaying noise level in dBA (NSCE), time: hours (Horas). Node placed at Corregidora and Pino Suárez in Historical Centre of México City 


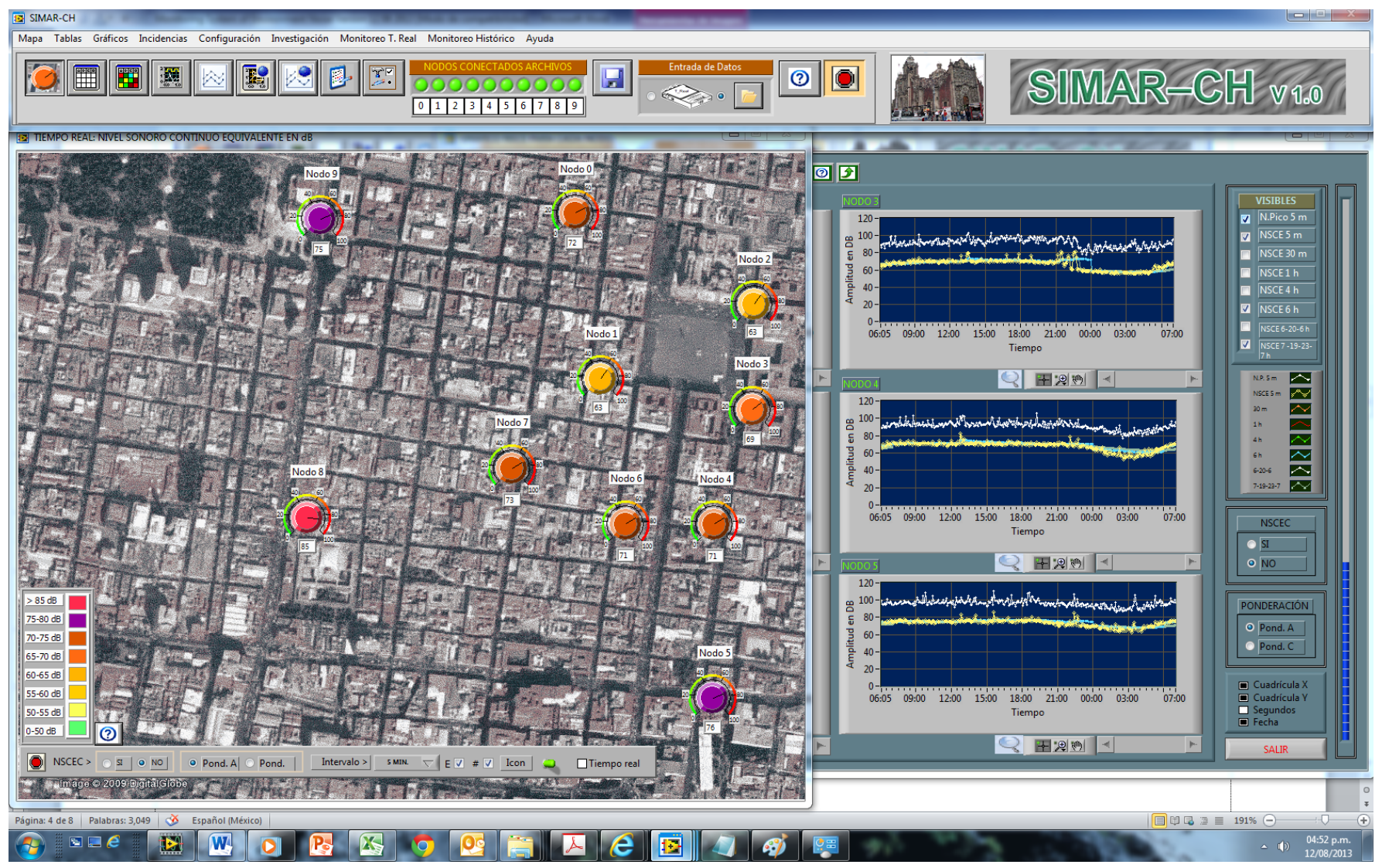

Fig. 5. Central server interface in the Control Centre

Table I presents some examples about noise pollution and its effects on health. The harmful effects are related with the exposure time, sound pressure level and its frequency range.

TABLE I. NOISE POLLUTION AND ITS EFFECTS ON HEALTH (SOME EXAMPLES)

\begin{tabular}{|c|c|c|c|}
\hline Effect & Exposure time & Sound pressure level & Frequency range \\
\hline Vibration on visual acuity [14]-[19] & Seconds & $110 \mathrm{~dB}$ & 4 a $800 \mathrm{~Hz}$ \\
\hline Human body vibration [19] & Seconds & $105 \mathrm{~dB}$ & 4 a $100 \mathrm{~Hz}$ \\
\hline Breathing frequency variation [14]-[17] & Seconds & $70 \mathrm{~dB}$ & $0.5-100 \mathrm{~Hz}$ \\
\hline Ear pain or discomfort [14]-[17] & Seconds & $110 \mathrm{~dB}$ & $50-8000 \mathrm{~Hz}$ \\
\hline Abdominal discomfort [16] & Seconds & $80 \mathrm{~dB}$ & $800 \mathrm{~Hz}$ \\
\hline Speech interference [14], [15] & Minutes & $50 \mathrm{~dB}$ & $100-4000 \mathrm{~Hz}$ \\
\hline Stress $[20]$ & Minutes & $105 \mathrm{~dB}$ & Whole range \\
\hline Endocrine disturbance [14]-[17] & Days & $80 \mathrm{~dB}$ & $3000-4000 \mathrm{~Hz}$ \\
\hline Sleep disturbance [21], [22] & $10-15$ events per night & $45 \mathrm{~dB}$ & Associated to aircraft noise \\
\hline Hearing threshold shift and loss [14]-[16] & Months & $80 \mathrm{~dB}$ & $3000-6000 \mathrm{~Hz}$ \\
\hline Vibro-acoustic disease [18] & Years & $90 \mathrm{~dB}$ & $<500 \mathrm{~Hz}$ \\
\hline Cardiovascular disease [15] & Years & $90 \mathrm{~dB}$ & $<500 \mathrm{~Hz}$ \\
\hline Hypertension [20]-[22] & Years & $50 \mathrm{~dB}$ & Associated to aircraft noise \\
\hline
\end{tabular}




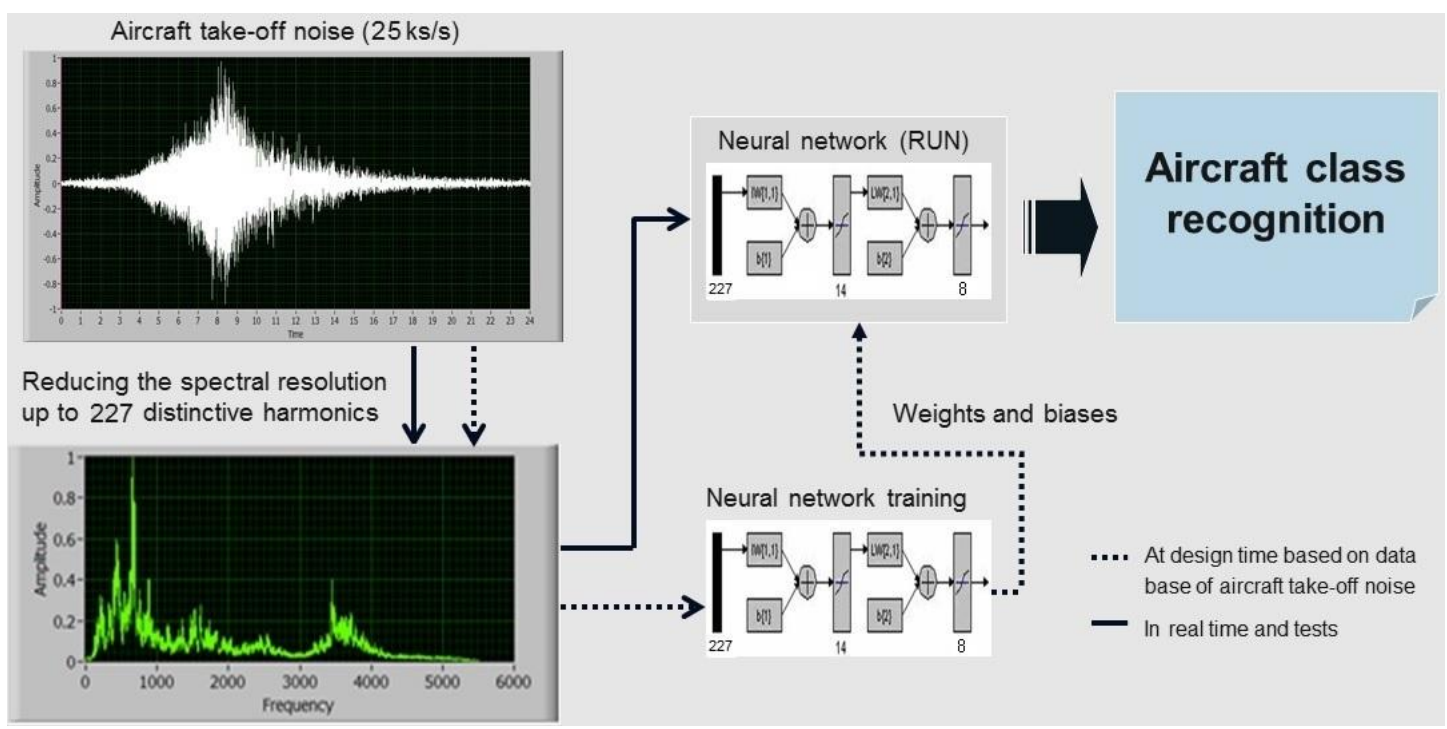

Fig. 6. System block diagram for the pattern generation and recognition

The spectral resolution (number of harmonics) must be reduced because of the following reasons:

1. The amplitude spectrum has 300000 harmonics and its processing will be very complex.

2. It is only of interest the spectral form.

The following suppositions are presented:

1. A reduction method of spectral resolution (with average spectrum) improves the processing results at initial and final times within the measurement interval of aircraft noise. In other words, a feedforward neural network was trained with one noise pattern which was acquired from zero seconds from the aircraft take-off until 24 seconds later; in run time, if the aircraft take-off noise is acquired from 5 seconds until 24 seconds, this time displacement of 5 seconds will affect little the spectral form if its spectral resolution has been reduced.

2. A moving average filter creates a typical form of the aircraft take-off noise spectrums.

3. Decimated average spectrums, with a rate $\mathrm{X}$, conserve the typical spectral form.

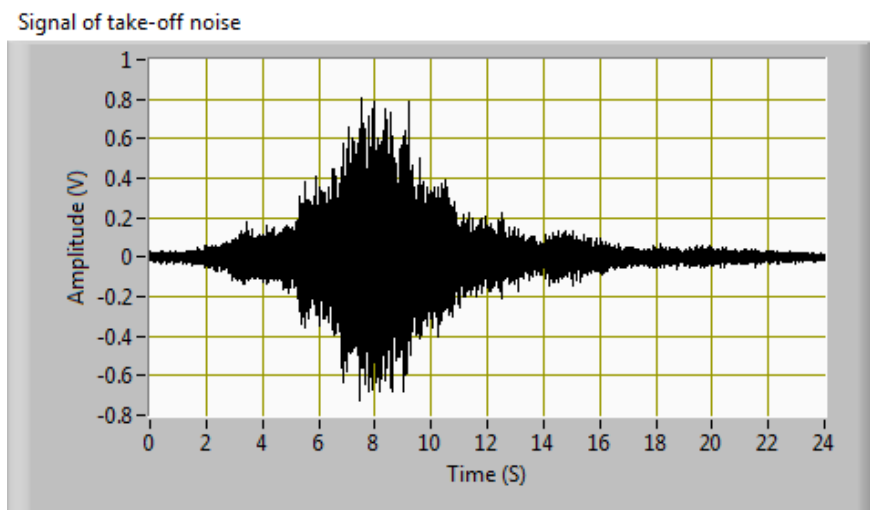

Fig. 7. Time-domain representation of typical signal of take-off noise with sampling frequency of $25 \mathrm{kHz}(25 \mathrm{ks} / \mathrm{s})$ for a Boeing 737-200

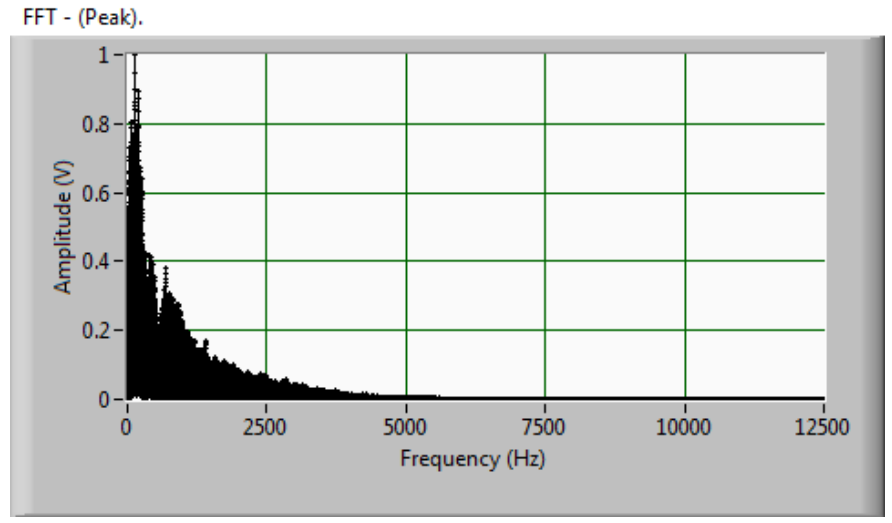

Fig. 8. Frequency-domain representation of the signal of Fig. 7

In this work was used the Bartlett-Welch method [11], [12], [13] for spectral estimation. The Bartlett method consists on dividing the received data sequence into a number $\mathrm{K}$, of non-overlapping segments and averaging the calculated Fast Fourier Transform. It consists of three steps:

1. The sequence of $\mathrm{N}$ points is subdivided in $\mathrm{K}$ non overlapping segments, where each segment has length $\mathrm{M}$.

$$
x_{i}(n)=x_{i}(n+i M), i=0,1, \ldots, K-1, n=0,1, \ldots, M-1
$$

2. For each segment, periodogram is calculated $\hat{P}_{x x}(f)$

$$
\hat{\mathrm{P}}_{\mathrm{xx}}(\mathrm{f})=\frac{1}{\mathrm{M}}\left|\sum_{\mathrm{n}=0}^{\mathrm{M}-1} \mathrm{x}_{\mathrm{i}}(\mathrm{n}) \mathrm{e}^{-\mathrm{j} 2 \pi \mathrm{fn}}\right|^{2}, \mathrm{i}=0,1, \ldots, \mathrm{K}-1
$$

3. The periodograms are averaged for the $\mathrm{K}$ segments and the estimation of the Bartlett spectral power can be obtained with (3). 


$$
\hat{\mathrm{P}}_{\mathrm{xx}}^{\mathrm{B}}(\mathrm{f})=\frac{1}{\mathrm{~K}}\left|\sum_{\mathrm{i}=0}^{\mathrm{K}-1} \hat{\mathrm{P}}_{\mathrm{xx}}^{(\mathrm{i})}(\mathrm{f})\right|^{2}
$$

Welch Method [13] unlike in the Bartlett method, the different data segments are allowed to overlap and each data segment is windowed.

$$
x_{i}(n)=x(n+i D), n=0,1, \ldots, M-1, i=0,1, \ldots, L-1
$$

Where iD is the point of beginning of the sequence $\mathrm{i}$-th. If $\mathrm{D}=\mathrm{M}$, the segments are not overlapped. If $\mathrm{D}=\mathrm{M} / 2$, the successive segments have $50 \%$ of overlapping and the obtained data segments are $\mathrm{L}=2 \mathrm{~K}$.

Why Welch method is introduced?

- Overlapping allows more periodograms to be added, in hope of reduced variance.

- Windowing allows control between resolution and leakage.

The Welch method is hard to analyze, but empirical results show that it can offer lower variance than the Bartlett method, but the difference is not dramatic.

- Suggestion is that $50 \%$ overlapping is used.

The data segment of 600000 samples, acquired in 24 seconds, is divided in 24 segments: $\mathrm{K}=24$, with $50 \%$ of overlapping, therefore, $\mathrm{L}=2 \mathrm{~K}=48$ overlapped data segments, later is applied the FFT (periodogram) to each segment and they are averaged. In this paper, 8 aircrafts types were tested. The rate of training/validation patterns per plane was $8 / 3$. The trained neural network was tested with 75 patterns in data base and several real time measurements performed in five days.

The Figs. 9, 10, 11 and 12 present an example of aircraft noise signals processed with this method.

The diminution of the spectral resolution allowed maintaining the spectral form with smaller amount of information for the neuronal network training.

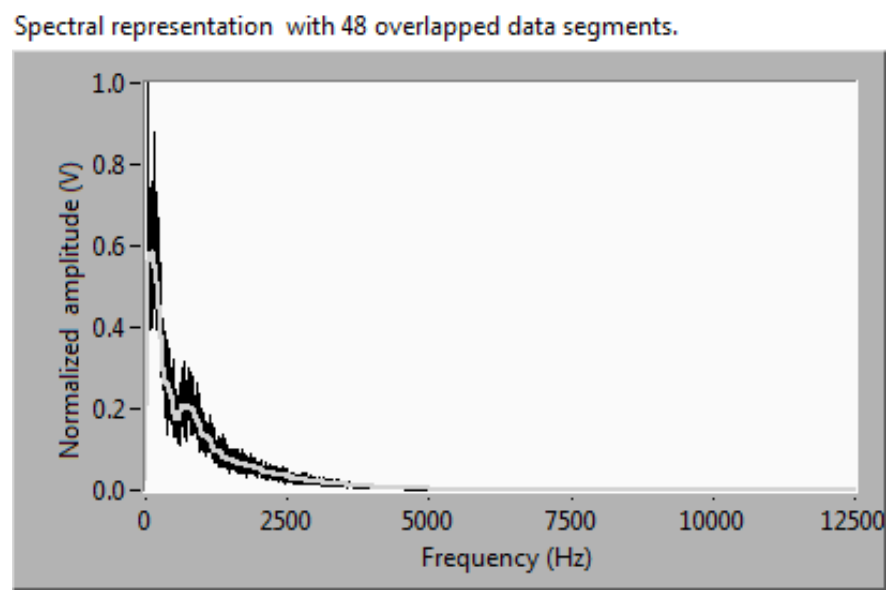

Fig. 9. Average spectral representation of 48 overlapped data segments, for a Boeing 737-200. Each segment has 25000 samples (one second). Filter rank $=50,12500$ harmonics. White curve is filtered with moving average filter

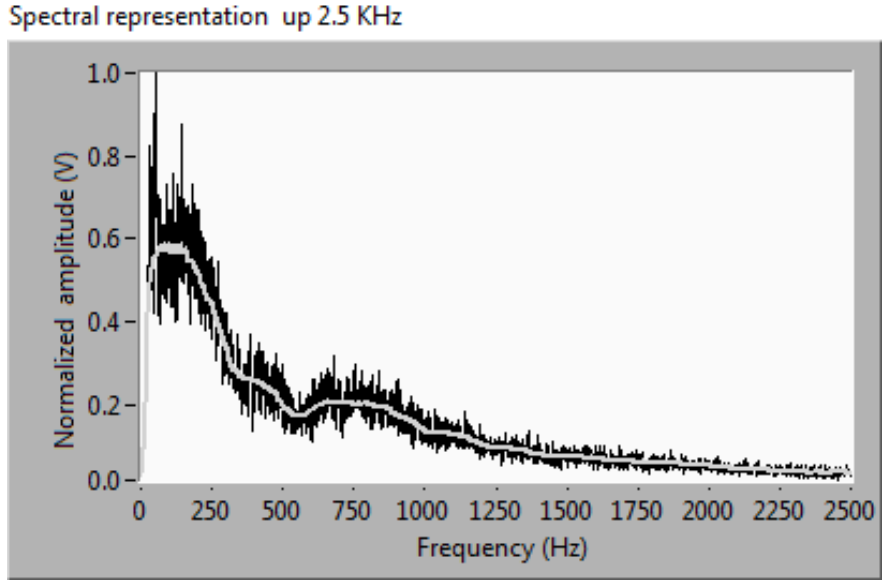

Fig. 10. Average spectral representation of Fig. 9, up 2.5 KHz. 2500 harmonics. White curve is filtered with moving average filter

Spectral representation up $2.5 \mathrm{KHz}$

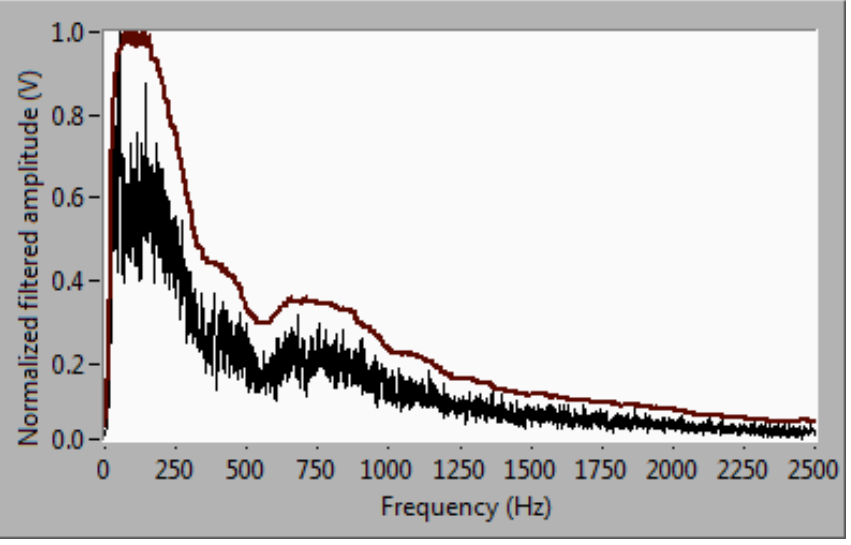

Fig. 11. The filtered curve is normalized

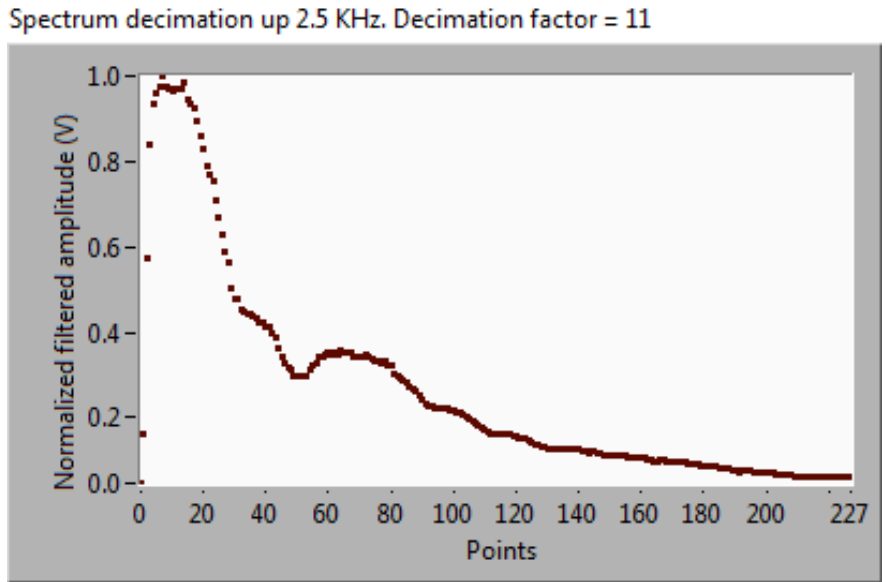

Fig.12. Normalized filtered curve with decimation. The 227 points (processed harmonics) are the neural network inputs 


\section{NEURAL MODEL AND PERFORMANCE EVALUATION}

The neural network has 227 inputs. Every input is a harmonic normalized and processed, an example was presented in Figs. 9 to 12. The output layer has 8 neurons, corresponding to the 8 recognized aircraft. After several tests, the neural network was successful with a hidden layer of 14 neurons. The activation functions are tan-sigmoid. The Fig 13 presents the topological diagram and training performance. The training performance was successful with an error of $1.12851 \mathrm{e}^{-10}$ in 300 epochs.
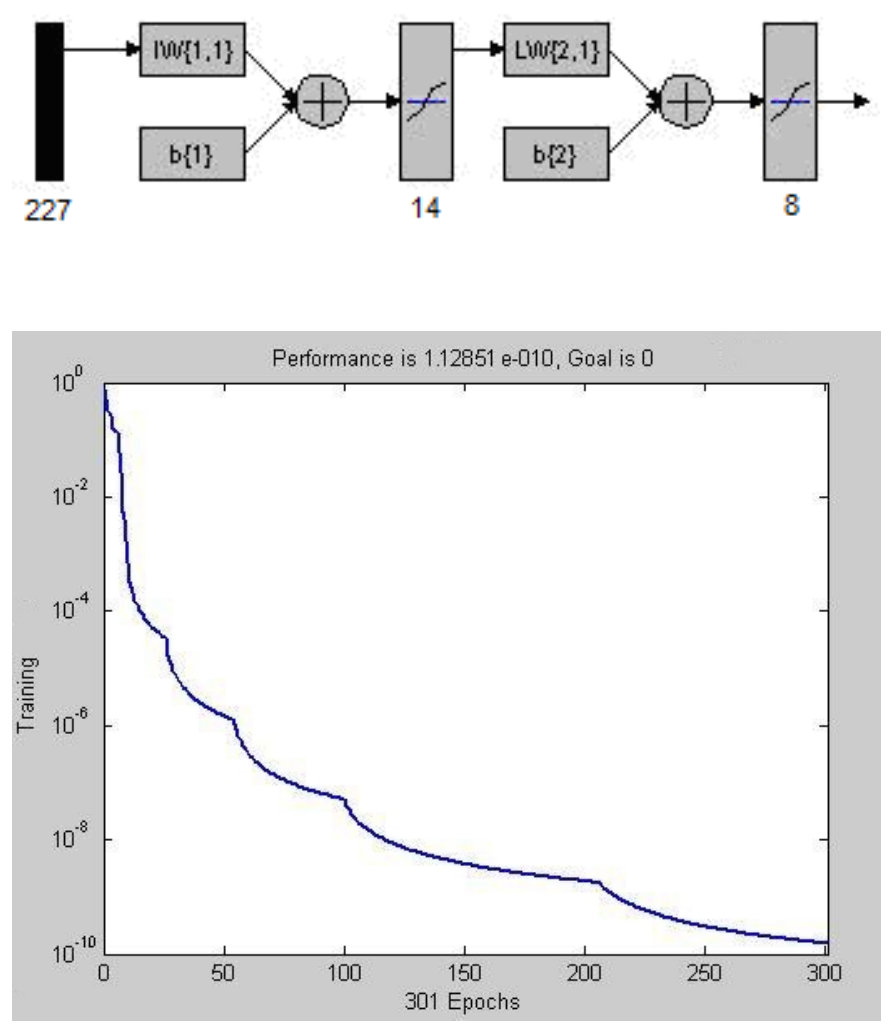

Fig. 13. Neural network topology and training performance. Input: 227 neurons (processed harmonics of aircraft noise). Output layer: 8 neurons (aircrafts type)

A test of aircraft recognition is presented in Table II. The average identification level is 65\%. Table III shows a performance evaluation, in percent of success, compared with the referenced method in [3]. The aircraft recognition methods using feature extraction with speech processing techniques [3], [4], [23], a neural model more complex and measurement segmentation in time [4], all in real environments, have higher performance than an aircraft recognition method whose signals were acquired in controlled environments and with preprocessed spectral features [24]. In this paper the methods are evaluated under similar conditions.
TABLE II. AIRCRAFT RECOGNITION RESULTS WITH PATTERNS IN DATA BASE

\begin{tabular}{|l|c|c|c|}
\hline \multicolumn{1}{|c|}{ AIRCRAFT CLASS } & $\begin{array}{c}\text { PATTERNS } \\
\text { FOR TEST }\end{array}$ & RECOGNIZED & $\begin{array}{c}\text { PERCENT OF } \\
\text { SUCCESS }\end{array}$ \\
\hline Airbus 1 & 8 & 5 & 62 \\
\hline Airbus 2 & 9 & 6 & 67 \\
\hline Airbus 3 & 9 & 5 & 55 \\
\hline $\begin{array}{l}\text { Airbus, Boeing } \\
\text { 737-800 }\end{array}$ & 10 & 7 & 70 \\
\hline Atr-42 & 6 & 4 & 67 \\
\hline $\begin{array}{l}\text { Boeing 737-100, } \\
737-200\end{array}$ & 14 & 9 & 64 \\
\hline $\begin{array}{l}\text { Boeing 737-600, } \\
737-700\end{array}$ & 12 & 8 & 67 \\
\hline Boeing 747-400 & 7 & 5 & 71 \\
\hline TOTAL & $\mathbf{7 5}$ & $\mathbf{4 9}$ & $\mathbf{6 5}$ \\
\hline
\end{tabular}

TABLE III. PerformanCE EVALUATION COMPARED to THE PUBLISHEDED METHOD [3] IN PERCENT OF SUCCESS.

\begin{tabular}{|l|c|c|}
\hline \multicolumn{1}{|c|}{$\begin{array}{c}\text { AIRCRAFT } \\
\text { CLASS }\end{array}$} & $\begin{array}{c}\text { PUBLICATED METHOD [3]. } \\
\text { (USING ONLY LINEAR } \\
\text { PREDICTION CODE) }\end{array}$ & $\begin{array}{c}\text { METHOD ANALYZED } \\
\text { IN THIS PAPER }\end{array}$ \\
\hline Airbus 1 & 80 & 62 \\
\hline Airbus 2 & 83 & 67 \\
\hline Airbus 3 & 66 & 55 \\
\hline $\begin{array}{l}\text { Airbus, Boeing } \\
\text { 737-800 }\end{array}$ & 71 & 70 \\
\hline Atr-42 & 100 & 67 \\
\hline $\begin{array}{l}\text { Boeing 737-100, } \\
\text { 737-200 }\end{array}$ & 72 & 64 \\
\hline $\begin{array}{l}\text { Boeing 737-600, } \\
\text { 737-700 }\end{array}$ & 77 & 67 \\
\hline Boeing 747-400 & 75 & $\mathbf{6 5}$ \\
\hline TOTAL & $\mathbf{8 0}$ & \\
\hline
\end{tabular}

\section{CONCLUSIONS AND FUTURE WORK.}

The system makes various types of spectral analyses and allows to obtain the main used statistical indicators for environment noise which can be expressed in $\mathrm{dB}(\mathrm{A})$ or $\mathrm{dB}(\mathrm{C})$ depending of the used weighting filter. Possible potential affectations to health can be determined, to different exposition times, which can give an idea of what can happen if the sonorous levels stay during a certain time.

The system allows making measurements of noise produced by airplanes at airport during take-offs. The 
measurement of the events is during 24 seconds, with sampling frequency of $25 \mathrm{KHz}$. The most representative frequencies of signal are below the $2.5 \mathrm{KHz}$.

Different analyses are developed, as well as the aircraft identification as much in real time, as in sounds stored previously, which have been stored without any class of processing. This allows that during a measurement simply the information of the take-offs is captured and later a deep analysis is made of the stored information.

The aircraft recognition based on their take-off acoustic impact improves to an environment noise monitoring system. The cited methods are robust to disturbances such as sounds of birds which they are near the microphone, barks, sounds of trucks, sounds of other airships which they are maneuvering within the airport, sounds generated in the houses near the point of measurement like music, works, even voices of the operators; in addition to the variations generated by the climate, the speed and the load of the airplane at the moment of the take-off.

The aircraft recognition methods using feature extraction with speech processing techniques, parallel or combined neural models and measurement segmentation in time [3], [4] or spatially are the appropriate technical-scientific recommendations for a best performance.

For future work, we will used spatial information to extract patterns related with aircraft position. This will improve the recognition performance and the acoustic impact estimation.

\section{REFERENCES}

[1] Kendall, M. EU proposal for a directive on the establishment of a community framework for noise classification of on civil subsonic aircraft for the purposes of calculating noise charges, European Union, 2003

[2] Holding, J. M.: Aircraft noise monitoring: principles and practice, IMC measurement and Control, vol. 34, issue 3, pp. 72-76, 2001.
[3] Sánchez, L., Sánchez, L. A., Carbajal, J., and Rojo, A. Aircraft Classification and Acoustic Impact Estimation Based on Real-Time Take-off Noise Measurements. Neural Processing Letters, 1-21, 2012.

[4] Sánchez-Pérez, L. A., Sánchez-Fernández, L. P., Suárez-Guerra, S. and Carbajal-Hernández, J. J. Aircraft class identification based on take-off noise signal segmentation in time. Expert Systems with Applications, 40, $5148-5159,2013$

[5] International Electrotech. Comm. (IEC): Standard IEC651: Sound Level Meters, 1979.

[6] Chu, W.: Speech Coding Algorithm: Foundation and Evolution of Standardized Coders, J. Wiley, 2003.

[7] Lochard - Airport Environment Management: EMU2100 Brochure, 2008.

[8] Perez-Meana, H. (ed.): Advances in Audio and Speech Signal Processing: Technologies and Applications, Idea Group Pub. 2007.

[9] International Electrotech. Comm. (IEC): Standard IEC1260: Octave Filters, 1995.

[10] American National Standards Institute (ANSI): Standard S1.11-2004: Specification for Octave-Band and Fractional-Octave-Band Analog and Digital Filters, 2004.

[11] Oppenheim, A.V., and R.W. Schafer. Discrete-Time Signal Processing. Englewood Cliffs, NJ: Prentice Hall, 1989. Pgs. 311-312.

[12] Sanchez, L. et al.: Noise pattern recognition of airplanes taking off: task for a monitoring system. Lecture Notes in Computer Science, vol. 4756, pp. 831-840, 2007.

[13] Welch, P.D. "The Use of Fast Fourier Transform for the Estimation of Power Spectra: A Method Based on Time Averaging Over Short, Modified Periodograms." IEEE Trans. Audio Electroacoust. Vol. AU-15 (June 1967). Pgs. 70-73.

[14] Kryter KD. The effects of noise in man: Academic Press; 1985.

[15] Berglund B, Lindvall T, Schwela DH. Guidelines for community noise: World Health Organization (WHO); 1999.

[16] Harris C. Handbook of acoustical measurements and noise control: McGraw-Hill; 1995.

[17] Berglund B, Lindvall T, Schwela DH. Community noise: World Health Organization (WHO); 1995.

[18] Alves-Pereira M, Castelo Branco N. Vibroacoustic disease2004.

[19] Recuero M. Ingeniería acústica: Paraninfo; 1994.

[20] Ostrosky-Solís F. Toc toc, ¿hay alguien ahí?: Infored; 2001.

[21] Michaud DS, Fidell S, Pearsons K, Campbell KC, Keith SE. Review of field studies of aircraft noise-induced sleep disturbance. J Acoust Soc Am 2007;121(1):32-41.

[22] Knipschild P. V. Medical effects of aircraft noise: Community cardiovascular survey. Int Arch Occ Env Hea 1977;40(3):185-90.

[23] Sánchez, L., Sánchez, L. A, Ibarra, M. Aircraft Classification and Noise Map Estimation Based on Real-Time Measurements of Take-off Noise, Proceedings of NCTA 2011 International Conference on Neural Computation Theory and Applications, Paris, France. 24-26 October, 2011, pp.153-161. ISBN: 978-989-8425-84-3.

[24] Sanchez, L., Pogrebnyak, O., Oropeza, J. and Suárez, S. Noise pattern recognition of airplanes taking off: task for a monitoring system. Lecture Notes in Computer Science, vol. 4756, pp. 831-840, 2007.

\section{Creative Commons Attribution License 4.0 (Attribution 4.0 International, CC BY 4.0)}

This article is published under the terms of the Creative Commons Attribution License 4.0 https://creativecommons.org/licenses/by/4.0/deed.en_US 